\title{
Quantification of levoglucosan and its isomers by High Performance Liquid Chromatography - Electrospray Ionization tandem Mass Spectrometry and its applications to atmospheric and soil samples
}

\author{
C. Piot ${ }^{1,2}$, J.-L. Jaffrezo ${ }^{2}$, J. Cozic ${ }^{2}$, N. Pissot ${ }^{1}$, I. El Haddad ${ }^{3,}{ }^{*}$, N. Marchand ${ }^{3}$, and J.-L. Besombes ${ }^{1}$ \\ ${ }^{1}$ Université de Savoie, LCME, Le Bourget du Lac, 73376, France \\ ${ }^{2}$ UJF-Grenoble 1, UMR5183, CNRS - LGGE Grenoble, 38041, France \\ ${ }^{3}$ Universités Aix-Marseille I, II et III, UMR6264, CNRS - LCP Marseille, 13331, France \\ *now at: Paul Scherrer Institut, Laboratory of Atmospheric Chemistry, Villigen PSI, Switzerland
}

Correspondence to: C. Piot (christine.piot@lgge.obs.ujf-grenoble.fr)

Received: 17 March 2011 - Published in Atmos. Meas. Tech. Discuss.: 18 July 2011

Revised: 3 January 2012 - Accepted: 9 January 2012 - Published: 12 January 2012

\begin{abstract}
The determination of atmospheric concentrations of levoglucosan and its two isomers, unambiguous tracers of biomass burning emissions, became even more important with the development of wood as renewable energy for domestic heating. Many researches demonstrated the increase during recent years of atmospheric particulate matter load due to domestic biomass combustion in developed countries. Analysis of biomass burning tracers is traditionally performed with Gas Chromatography-Mass Spectrometry (GCMS) technique after derivatization and requires an organic solvent extraction. A simpler and faster technique using Liquid Chromatography - Electrospray Ionisation - tandem Mass Spectrometry (LC-ESI-MS/MS) was optimized for the analysis of levoglucosan, mannosan and galactosan isomers after an aqueous extraction. This technique allows a good separation between the three compounds in a very reduced time (runtime $\sim 5 \mathrm{~min}$ ). LOD and LOQ of this method are $30 \mu \mathrm{g}^{-1}$ and $100 \mu \mathrm{g} \mathrm{l}^{-1}$ respectively, allowing the use of filters from low-volume sampler (as commonly used in routine campaigns). A comparison of simultaneous levoglucosan measurements by GC-MS and LC-ESI-MS/MS for about 50 samples coming from different types of sampling sites and seasons was realized and shows very good agreement between the two methods. Therefore LC-ESI-MS/MS method can be used as an alternative to GC-MS particularly for measurement campaigns in routine where analysis time is important and detection limit is reduced. This paper shows that this method is also applicable to other environmental sample types like soil.
\end{abstract}

\section{Introduction}

A growing number of scientific studies have recently focused on the apportionment of biomass burning emissions in ambient aerosol (Zheng et al., 2002; Puxbaum et al., 2007; Gaeggeler et al., 2008; Caseiro et al., 2009). This primary source emits high amounts of organic aerosol (OA) and can largely contribute to the organic carbon (OC) mass of particulate matter (PM) in winter. For example in Europe, biomass burning contributions to $\mathrm{OC}$ in winter have been estimated to be around 30, 35, 35 and $41 \%$ in Oslo (Norway) (Yttri et al., 2009), Vienna (Austria) (Caseiro et al., 2009), Ghent (Belgium) (Zdráhal et al., 2002) and Zürich (Switzerland) (Szidat et al., 2006) respectively and contributions to organic matter in winter is $68 \%$ in Grenoble (France) (Favez et al., 2010). Contributions of this source to total PM mass in winter are about $20 \%$ in Paris (France) (Favez et al., 2009) and $42 \%$ in Grenoble (France) (Favez et al., 2010). Better source apportionment studies, especially addressing biomass burning contributions, will be mandatory in the near future in order to respect tougher European Union regulations of the aerosol mass (EU-Directive 2008/50/CE).

OA emitted by biomass burning is particularly rich in carcinogenic compounds, such as polycyclic aromatic hydrocarbons (Simoneit, 2002 and references therein). Among the myriad of molecular compounds emitted by biomass burning, the three isomeric anhydrous sugars levoglucosan (1,6anhydro-B-D-glucopyranose), mannosan, and galactosan, formed during pyrolysis of cellulose and hemicellulose $(\mathrm{Ca}-$ seiro et al., 2009), are the predominant organic species

Published by Copernicus Publications on behalf of the European Geosciences Union. 
(Simoneit et al., 1999). Levoglucosan is the most abundant anhydrous sugar among the monosaccharide anhydrides ( $\mathrm{Si}-$ moneit et al., 1999). In addition, levoglucosan considered to be reasonably stable in the atmosphere (Fraser and Lakshmanan, 2000) is used since the 1980s as a key marker for the apportionment of biomass burning emissions (Hornig et al., 1985; Locker, 1988) particularly used in CMB modelling (Fraser and Lakshmanan, 2000). Recently, Hoffman et al. (2010) nevertheless pointed out the potential oxidation of levoglucosan by $\mathrm{OH}$ radicals in the aqueous phase of aerosols. Moreover, Hennigan et al. (2010) estimated a loss of levoglucosan between 20 and $90 \%$ during smoke plume aging for typical summer conditions. These results should be carefully considered for aged air masses and taken into account when using this tracer for biomass burning apportionment. Another key parameter in biomass burning apportionment are the ratios of levoglucosan-to-mannosan and levoglucosan-to-galactosan that are somewhat specific of wood types, allowing the differentiation between hardwood and softwood combustion (Schmidl et al., 2008). For instance, levoglucosan-to-mannosan ratio is about 17 for American beech combustion and about 4 for White spruce combustion (Fine et al., 2004). So, the simultaneous analysis of the three monosaccharides is an important issue for biomass burning study, notably for the choice of wood burned profile in source apportionment models.

Very few studies deal with monosaccharide anhydrides in environmental compartments other than in the atmosphere: Simoneit et al. (2004) and Otto et al. (2006) studied soil samples, Schkolnik et al. (2005) looked at rainwater and Fabbri et al. (2008) focused on lignites. However, these studies seem to indicate that monosaccharide anhydrides could be used as proxies for the detection of the impact of biomass burning events in many types of matrices.

Analysis of molecular markers is traditionally performed using Gas Chromatography-Mass Spectrometry (GC-MS) technique after organic solvent extraction and derivatization steps (Bergauff et al., 2008). Widely used for the chemical characterization of atmospheric aerosol, this method is also used for the analysis of soil samples (Simoneit et al., 2004; Otto et al., 2006). Even though the reliability of this approach is demonstrated in several studies, it requires intensive sample preparation. In addition, the derivatization step usually based on a silylation reaction prevents the analysis of aqueous samples. Recently, other analytical methods without derivatization step were developed for monosaccharide anhydrides quantification using liquid chromatography. For example Schkolnik et al. (2005) used ion-exclusion chromatography coupled with a spectroscopic detection to analyse directly rainwater. More recently High Performance Liquid Chromatography (HPLC) was coupled with various detectors to detect sugar compounds, including pulsed amperometric detection (PAD) (Engling et al., 2006; Caseiro et al., 2007), aerosol charge detection (ACD) (Dixon and Baltzell, 2006), Mass Spectrometry (MS) (Dye and Yttri,
2005; Wan and Yu, 2006; Gambaro et al., 2008; Saarnio et al., 2010). Iinuma et al. (2009) have developed another analytical method based on High Performance AnionExchange Chromatography (HPAEC) coupled with a PAD detector. Although this method allows the determination of several tracers of biomass burning, only levoglucosan is quantified among the three isomeric anhydrous sugars. Liquid Chromatography coupled with Electrospray Ionisationtandem Mass Spectrometry (ESI-MS/MS) was also proposed by Palma et al. (2004). But also in this case their analytical conditions do not allow the quantification of levoglucosan isomers.

In this study, we present a new method based on coupling anion-exchange chromatography and Electrospray Ionisation-tandem Mass Spectrometry (ESI-MS/MS), which provides an appropriate separation of the monosaccharide anhydride isomers, a sensitive detection, and a fast analysis. Tandem Mass Spectrometry allows a better selectivity of compounds by selecting daughter ion characteristics of the studied compounds (levoglucosan and its isomers). This method allows the analysis in the aqueous phase and is therefore applicable to a wide variety of environmental samples including atmospheric aerosol, soil and water (rain, snow, ice) samples.

Moreever, only few papers have compared the analytical performance of different methods with the more widely used GC-MS technique (Schkolnik et al., 2005; Engling et al., 2006). In this study, atmospheric samples from different sites and seasons were simultaneously analyzed with HPLC-ESI-MS/MS method (called LC-MS) and with the derivatization-GC-MS method in order to compare their analytical performances. The application of the HPLC-ESIMS/MS method to levoglucosan quantification in soil sample is also presented.

\section{Material and methods}

\subsection{Reagents and materials}

Authentic standards used in this study include levoglucosan (1,6-anhydro- $\beta$-D-glucopyranose) $99.0 \%$ (CAS 49807-7, Sigma-Aldrich, Steinheim, Germany), mannosan (1,6-anhydro- $\beta$-D-mannopyranose) (CAS 14168-65-1, Carbosynth, Compton, UK) and galactosan (1,6-anhydro- $\beta$-Dgalactopyranose) (CAS 644-76-8, TRC, Toronto, Canada). Standard solutions, sample extraction, and mobile phase solutions were prepared with ultrapure water 18.2 mega Ohm grade (Purelab Ultra system, Elga, High Wycombe, UK). Stock solutions at $10 \mathrm{gl}^{-1}$ were prepared by dissolving $1.00 \mathrm{~g}$ of each compound in $100 \mathrm{ml}$ of ultrapure water. These solutions were stored in amber glass bottles (SCHOTT® Duran $\left(\right.$ ) ) at $4{ }^{\circ} \mathrm{C}$. Sodium hydroxide solutions for the mobile phase were prepared from a $50 \%(w / w) \mathrm{NaOH}$ solution 
(J. T. Baker). Ultrapure water was degassed with He before $\mathrm{NaOH}$ addition in order to limit carbonate formation.

\subsection{Sample collection and LC-MS extraction}

Atmospheric particulate matter of less than $10 \mu \mathrm{m}$ and $2.5 \mu \mathrm{m}$ diameter $\left(\mathrm{PM}_{10}\right.$, and $\mathrm{PM}_{2.5}$, respectively) were collected onto QM-A quartz fiber filters (Whatman, $150 \mathrm{~mm}$ diameter) in a high-volume sampler (flow rate $30 \mathrm{~m}^{3} \mathrm{~h}^{-1}$ ) with collection times of 12 or $24 \mathrm{~h}$. Samples were collected in two urban background sites in France: "Les Frênes" in Grenoble and "Cinq Avenues" in Marseille, during autumn to winter 2009 and summer 2008, respectively, during the FORMES program (Favez et al. 2010; El Haddad, 2011a, b). After collection, samples were packed in aluminum foil, sealed in polyethylene bags and stored at $-20^{\circ} \mathrm{C}$. Blank filter samples were performed in order to estimate the contamination. Concentrations of biomass burning tracers in blank filter samples were always below the detection limits of the two analytical methods used (see detection limits Sect. 3.1).

Soil samples were collected in the top soil horizon (between two and five cm depth) located under a charcoal burning two days after the end of the combustion, in the karstic Vercors massif (French Alps). After collection, they were air dried at room temperature and sieved at $2 \mathrm{~mm}$.

Appropriate atmospheric sample fractions ( 3 to $12 \mathrm{~cm}^{2}$ ) and soil sample fractions of $5 \mathrm{~g}$ were extracted with $15 \mathrm{ml}$ and $5 \mathrm{ml}$, respectively, of ultrapure water with a vortex agitation during $20 \mathrm{~min}$. Longer agitation and ultrasonic agitation were also tested. In order to evaluate extraction recoveries of the two extraction methods (ultrasonic or vortex agitation), blank Whatman QM-A filters were spiked in triplicate with a standard solution containing the three monosaccharides in aqueous solvent at low, medium and high concentrations $\left(100,500\right.$, and $\left.1000 \mu \mathrm{g}^{-1}\right)$. They were air dried at room temperature in order to evaporate the aqueous solvent. The results are discussed in Sect. 3.1.

Just before the analysis, extracts were further filtered using Acrodisc ${ }^{\circledR}$ filters (Pall, Gelman) with a porosity of $0.22 \mu \mathrm{m}$ previously rinsed with $40 \mathrm{ml}$ of ultrapure water. Soil sample extracts were previously filtered using pleated filter cellulose paper.

\subsection{LC-MS analysis}

Sample was analyzed using High Performance Liquid Chromatography - Electrospray Ionisation - tandem Mass Spectrometry (HPLC-ESI-MS/MS) like presented by Piot et al. (2009). Liquid chromatography is performed with a Dionex pump (model DX500) mounted with Peek and vacuum degasser. Sample is injected by a $449 \mu$ injection loop. The separation is carried out at room temperature (about $20^{\circ} \mathrm{C}$ ) using a Carbopac PA-1 anion-exchange analytical column $(250 \mathrm{~mm} \times 4 \mathrm{~mm}$, Dionex $)$ coupled with a Carbopac PA-1 guard column $(50 \mathrm{~mm} \times 4 \mathrm{~mm}$, Dionex $)$
Table 1. Instrumental conditions.

\begin{tabular}{lr}
\hline Spray voltage $(\mathrm{kV})$ & 6.44 \\
\hline Spray current $(\mu \mathrm{A})$ & 4.46 \\
Shealth gas flow rate & 40.84 \\
Auxillary gas flow rate & 21.32 \\
Sweep gas flow rate & 12.03 \\
Capillary temperature $\left({ }^{\circ} \mathrm{C}\right)$ & 310.07 \\
\hline
\end{tabular}

like in Caseiro et al. (2007). Elution is achieved in isocratic mode at $1.2 \mathrm{ml} \mathrm{min}^{-1}$ with $0.5 \mathrm{mM}$ sodium hydroxide solution. Columns are flushed and equilibrated between two samples with an elution gradient between 0.5 and $3 \mathrm{mM}$ sodium hydroxide at a $1.2 \mathrm{ml} \mathrm{min}^{-1}$ flow rate (run time: $9 \mathrm{~min}$ ). During this step, the mobile phase is not injected into the MS. Columns are washed overnight (after approximately 20 samples) with an elution gradient between 0.5 and $200 \mathrm{mM}$ sodium hydroxide at a $0.5 \mathrm{ml} \mathrm{min}^{-1}$ flow rate (run time: $15 \mathrm{~h}$ ).

A micrometric split valve is used to reduce the flow injected to the MS at $0.8 \mathrm{ml} \mathrm{min}^{-1}$. The analytical detector is an Electrospray Ionization Ion Trap MS (LCQ Fleet MS, Thermo Fisher Scientific). Detection is achieved in the negative ion mode like in Gambaro et al. (2008) with a $m / z 161$ trap isolation. Parameters are optimized for the best Collision Induced Dissociation (CID) efficiency with selective current in $m / z 101$ and $m / z 113$, characteristic of daughter ions of levoglucosan and its two isomers. Instrumental conditions are reported in Table 1. Chromatogram integration is realized on the selective current: $m / z 101 \pm 0.5+113 \pm 0.5$.

Calibration is performed twice, at the beginning of the analysis sequence and at the end of the sequence, with standard solutions containing the three monosaccharides at 100 , 500 , and $1000 \mu \mathrm{g} 1^{-1}$. Samples and standard solutions are injected twice for each analysis.

\subsection{GC-MS analysis}

Standards and atmospheric samples are simultaneous analyzed by GC-MS as described in El Haddad et al. (2009). Authentic standard solutions were prepared in acetone and stored at $4{ }^{\circ} \mathrm{C}$. Briefly, sample fractions are extracted with a dichloromethane/acetone mix (1:1 v/v) using an Accelerated Solvent Extractor (ASE 200, Dionex) and reduced to a volume of $1 \mathrm{mlL}$. A $100 \mu \mathrm{l}$ extract fraction is trimethylsilylated with $100 \mu \mathrm{l}$ of N,O-bis(trimethylsilyl)-trifluoroacetamide (BSTFA) containing 1\% trimethylchlorosilane (TMCS) for two hours at $50^{\circ} \mathrm{C}$. This fraction is then analysis with a HP 6890 Gas Chromatograph coupled with a HP 5973 Mass Selective detector (Agilent Technologies). Sample of $1 \mu \mathrm{l}$ is injected in a splitless mode in an Optima 5 Accent column (Macherey-Nagel). Quantification is performed using 
Table 2. Analytical performances and linear regression parameters of levoglucosan (same performances for mannosan and galactosan).

\begin{tabular}{|c|c|c|}
\hline & LC-MS & GC-MS \\
\hline $\operatorname{LOD}^{\mathrm{a}}\left(\mu \mathrm{g} 1^{-1}\right)$ & 30 & 100 \\
\hline Masse LOD ( $\mu \mathrm{g})$ & 0.06 & 0.1 \\
\hline $\operatorname{LOQ}^{\mathrm{b}}\left(\mu \mathrm{g} 1^{-1}\right)$ & 100 & 333 \\
\hline Analytical concentration range $\left(\mu \mathrm{g} 1^{-1}\right)$ & $20-200$ & $100-5.10^{5}$ \\
\hline RSD for high concentration $^{c}(\%)$ & 10 & 3 \\
\hline RSD for low concentration $^{c}(\%)$ & 5 & 5 \\
\hline$R^{2}$ & 0.996 & 0.963 \\
\hline
\end{tabular}

a $3 \times$ Standard deviation of the blank; ${ }^{b} 10 \times$ standard deviation of the blank;

${ }^{c}$ successively 5 injections of standard solution.

selected ion current peak areas (204 for levoglucosan and mannosan and 217 for galactosan) and calibration curves are established with authentic standards and a deuterated levoglucosan internal standard. Calibration was checked every 10 samples and is performed with 8 levels of concentration between 2 and $400 \mathrm{mg}^{-1}$.

\section{Results and discussion}

\subsection{Methods Performance}

The elution conditions used in the LC-MS method allow the detection of the three monosaccharides in less than $6 \mathrm{~min}$ with a very good separation (Fig. 1a). The levoglucosan retention time is about 2.3 min followed successively by mannosan, and galactosan. The chromatogram shows a high resolution (Rs: peak resolution) between the three peaks (Rs $=1.25$ for levoglucosan and mannosan and Rs $=1.65$ for mannosan and galactosan) in a very reduced time (runtime $\sim 5 \mathrm{~min}$ ). However, this method allows only the analysis of levoglucosan and its two isomers. All analytical performance and linear regression parameters for LC-MS calibration are presented in Table 2. Limit of detection (LOD) of the analytical method presented in this paper (3 times the standard deviation of the blank) is $30 \mu \mathrm{g} 1^{-1}$ and the limit of quantification (LOQ) (10 times the standard deviation of the blank) is $100 \mu \mathrm{g}^{-1}$ (Table 2). The analytical concentration range was 20 to $2000 \mu \mathrm{g} 1^{-1}$.

Calibration curves systematically show $R^{2}$-values above 0.996 for the three compounds. Analytical reproducibility, evaluated by the relative standard deviation (RSD) between five successive injections of the same standard solution at concentrations of 500 and $1000 \mu \mathrm{g} 1^{-1}$, ranges between 5 to $10 \%$. In conditions of extraction allowing two injections and the analysis of a sample, mass LOD is $60 \mathrm{ng}$.

The analysis of levoglucosan by GC-MS is traditionally conducted after an organic solvent extraction using dichloromethane (Simoneit et al., 1999) or mixture of dichloromethane and methanol (Simoneit, 2002). In the case of HPLC analysis, some studies used a water extraction assisted by ultrasonic or short vortex agitation to extract saccharides because of their high solubility in water (Schkolnik et al., 2005; Engling et al., 2006; Caseiro et al., 2007). In this study, the efficiency of these two water extraction procedures was tested. Blank filters were spiked in triplicate $(100 \mu l$ or $500 \mu \mathrm{l}$ ) with three standard aqueous solutions (more or less concentrated) containing the three monosaccharides at low, medium and high concentrations (representing 0.5, 2.5, and $5 \mu \mathrm{g}$ of each compound respectively), in order to cover the whole calibration range. After drying at room temperature, those filters were then extracted with $5 \mathrm{ml}$ of aqueous solvent. Extraction was tested both by 20 min ultrasonic agitation and by $20 \mathrm{~min}$ short vortex agitation. With the latter, the average recoveries were $90 \pm 9 \%, 88 \pm 28 \%$, and $99 \pm 9 \%$ for levoglucosan, mannosan, and galactosan respectively. Average ultrasonic agitation recovery was $13 \pm 5 \%$ lower than for the short vortex agitation method, for the three monosaccharides. Performance is not improved by longer short vortex agitation but extraction time seems to be important for ultrasonic agitation. Caseiro et al. (2007) showed the best reproducibility $(100 \pm 8 \%)$ for an extraction time of $45 \mathrm{~min}$. Therefore, all further work was performed with short vortex agitation and all results for levoglucosan were corrected using an average extraction efficiency of $92 \%$. In addition, with this method, the minimum solvent extraction volume is about $2 \mathrm{ml}$ allowing the filtration step and two successive LC-MS analyses of the sample. In these conditions the maximum extracted filter fraction is $4.5 \mathrm{~cm}^{2}$ representing $21 \mathrm{~m}^{3}$ of collected air for a sampling at $30 \mathrm{~m}^{3} \mathrm{~h}^{-1}$ during $24 \mathrm{~h}$ onto a $150 \mathrm{~mm}$ quartz fiber filters.

GC-MS analysis was optimized to quantify about twenty compounds including monosaccharide anhydrides, acids, methoxyphenols and sterols (details in El Haddad et al., 2009). Levoglucosan retention time with GC-MS method $(17.98 \mathrm{~min})$ is much longer than with the LC-MS method (Fig. 1b). In our chromatographic conditions, elution of three monosaccharides is in the following order: galactosan, mannosan, and levoglucosan (Fig. 1b). The analytical concentration range is $100 \mu \mathrm{g} \mathrm{l}^{-1}$ to $500 \mathrm{mg} \mathrm{l}^{-1}$. Calibration curves for the three monosaccharides show $R^{2}$-values above 0.963 (Table 2). RSD range between $3 \%$ and $5 \%$ for high and low concentrations analysis, respectively. LOD and LOQ of GC-MS analysis are $100 \mu \mathrm{g} 1^{-1}$ and $333 \mu \mathrm{g} 1^{-1}$, respectively (Table 2). These concentrations correspond to a mass LOD of $100 \mathrm{ng}$ for the extraction and analysis conditions described in the experimental part. The GC-MS analytical performances could be enhanced by increasing the preconcentration of the sample. However, this lowering of the final volume would hamper the successive analyses of derivatized and non derivatized samples to be performed for a full particulate organic matter characterization. In addition, a low volume sample may lead to a loss of reproducibility or performances. 

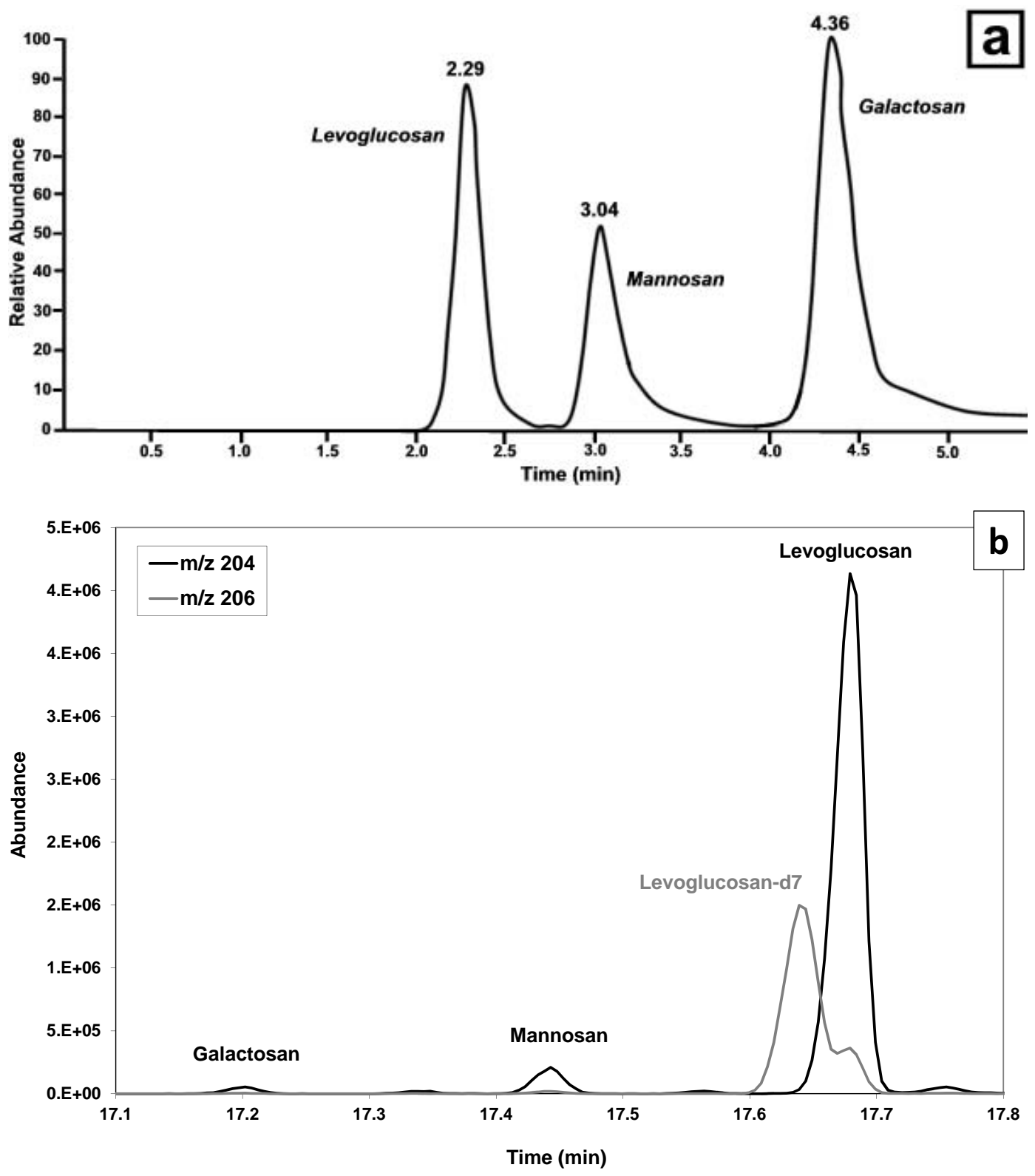

Fig. 1. LC-MS chromatogram (a) and GC-MS chromatogram on selective $m / z$ (b).

In order to evaluate recoveries by the GC-MS analysis method, filters are spiked in duplicate with $500 \mu$ of levoglucosan standard solutions in acetone at low, medium, and high concentrations. Those concentrations represent 1 , 10 , and $250 \mu \mathrm{g}$ of each compound by filter, respectively, after solvent evaporation at room temperature. After ASE extraction the samples were concentrated to $1 \mathrm{ml}$ solution before the derivatization step and the analysis. In these conditions, the recovery for levoglucosan extraction with dichloromethane/acetone mix solvent is $73 \pm 8 \%$.

LOD and LOQ of both methods are in the same order of magnitude (Table 2) but LC-MS LOD is lower than the GCMS one's. LC-MS shows better analytical performance for the quantification of the lower levoglucosan concentrations. However, for larger concentrations, this method has a lower reproducibility with a RSD value reaching $10 \%$.

Minimum solvent extraction volume for the GC-MS method is about $60 \mathrm{ml}$ of organic solvent mix that is thirty times more than LC-MS method (extraction with a minimum of $2 \mathrm{ml}$ of aqueous solvent). In addition, LC-MS method uses aqueous solvent, thus minimizing the waste management of the analysis. Another advantage of the aqueous extraction is that the same water aliquot may be used for further compound analysis like that of ions or of other water soluble organic compounds. 
In addition, with these optimized extraction conditions $\left(4.5 \mathrm{~cm}^{2}\right.$ in $2 \mathrm{ml}$ of solvent) and for a $720 \mathrm{~m}^{3}$ sampling collected on QM-A quartz fiber filters (impacted surface $=153.9 \mathrm{~cm}^{2}$ ), LC-MS shows an atmospheric concentration LOD of $2 \mathrm{ng} \mathrm{m}^{-3}$. For the same extraction surface area and sampling conditions, the GC-MS method has an atmospheric concentration LOD of $5 \mathrm{ng} \mathrm{m}^{-3}$. LC-MS allows to reach lower levels of atmospheric concentration for the same extracted surfaces of filter.

\subsection{Comparison of LC-MS and GC-MS analysis to atmospheric applications}

Parallel analyses were conducted by LC-MS and GC-MS methods on the same fifty atmospheric samples (a different fraction of each sample was analyzed with each method). Samples were collected during different seasons between summer 2008 and winter 2009 in two urban background sites located in Marseille and Grenoble, the second and the sixteenth most populated city in France respectively. Sampling of $360 \mathrm{~m}^{3}$ and $720 \mathrm{~m}^{3}$ were collected with High-Volume samplers. Concentrations were corrected by extraction efficiencies. Levoglucosan concentrations covered a wide range from 4 to $3200 \mathrm{ng} \mathrm{m}^{-3}$ and concentrations found are in the same range as previous measurements reported in Europe. For instance, Caseiro et al. (2009) measured concentrations ranging from 20 to $400 \mathrm{ng} \mathrm{m}^{-3}$ of levoglucosan in Austrian Regions and Puxbaum et al. (2007) measured 0.3 to $1651 \mathrm{ng} \mathrm{m}^{-3}$ in CARBOSOL sites.

Comparison between the two methods was only made for levoglucosan since concentrations of the other monosaccharide anhydrides (mannosan and galactosan) were lower than the detection limit for too many samples. Results show an excellent agreement between the LC-MS and GC-MS methods, with a slope of almost unity, within the uncertainty of the measurement, and $R^{2}$-values of 0.94 (Fig. 2). This comparison validates the LC-MS method versus the more traditional GC-MS method for the analysis of atmospheric levoglucosan. With a lower detection limit for atmospheric analysis and faster sample treatment, LC-MS method represents a very good alternative to the widely used GC-MS method. With this method, quantification of levoglucosan could be achieved in low-volume sampling conditions and for field campaigns with many samples.

Several such studies are in progress in our labs in different environment type (rural, urban, alpine sites,...), including collections with low volume samplers $\left(1 \mathrm{~m}^{3} \mathrm{~h}^{-1}\right)$ for week-long sampling, and for a year-long survey of eight urban background sites in the Rhône-Alpes Region (Piot, 2011; Piot et al., 2011) where measured levoglucosan concentrations range between $4 \mathrm{ng} \mathrm{m}^{-3}$ (in summer) and $1000 \mathrm{ng} \mathrm{m}^{-3}$ (in winter).

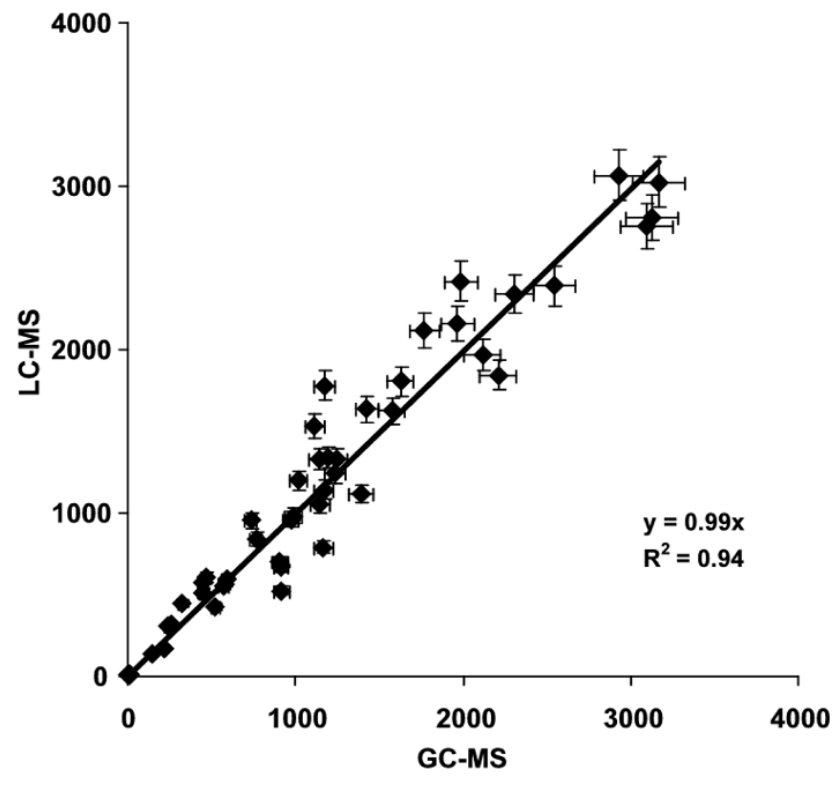

Fig. 2. Correlation between LC-MS results and GC-MS results for levoglucosan. (50 samples analysed). Concentrations are in $\mathrm{ng} \mathrm{m}^{-3}$ in air. Error bars represent the RSD.

\subsection{Other environmental samples analysis}

The use of aqueous solvent for levoglucosan extraction in the LC-MS method allows to consider the analysis of monosaccharide anhydrides in many environmental matrices. Levoglucosan and its two isomers were analyzed by the LC-MS method in soil samples collected under wood fire combustion ( 2 to $5 \mathrm{~cm}$ depth) two days after the end of a combustion performed to produce charcoal. Extraction with Soxhlet and dichloromethane, and analyses using GC-MS were performed but no monosaccharide anhydrides were observed in these analytical conditions. Water extraction $(5 \mathrm{~g}$ of soil extract with $5.0 \mathrm{ml}$ of water during $20 \mathrm{~min}$ of short vortex agitation) was undertaken and followed by LC-MS analysis. In these conditions, concentrations of $10.0,1.5$ and $0.6 \mu \mathrm{g} \mathrm{g}^{-1}$, were measured for levoglucosan, mannosan and galactosan, respectively, highlighting a noteworthy impact of fire combustion on soil. Otto et al. (2006) have analyzed charred pine forest surface soil samples in Canada by GC-MS after organic solvent extraction and have measured levoglucosan, mannosan and galactosan concentrations of 1.0, 0.6, and $0.3 \mu \mathrm{g} \mathrm{g}^{-1}$, respectively. Simoneit et al. (2004) measured levoglucosan concentrations of less than $0.1 \mu \mathrm{g} \mathrm{g}^{-1}$ in soil or soil dust weakly impacted by biomass burning. Thus, data reported in the literature are much lower than concentrations measured in this study. This may be related to the type of soil samples, or maybe due to a better efficiency of water extraction than organic solvent extraction for soil samples. Additional tests would be necessary to compare aqueous and organic solvent extraction methods but test samples of soil with certified levoglucosan concentrations do not exist 
in order to quantify the extraction efficiency. However, the analysis of levoglucosan in soil, easily achievable with the LC-MS method with a low detection limit, is a promising way that can allow to evaluate the impact of forest fires in such environmental archives.

\section{Conclusions}

Levoglucosan concentrations of atmospheric samples obtained with two independent methods (LC-MS and GC-MS) were compared and present extremely good correlation for a wide range of concentrations. This shows the validity of our HPLC-ESI-MS/MS measurements for the fast quantification of levoglucosan. Whereas the GC-MS allows the detection of a large number of compounds and can handle large atmospheric concentration range, the LC-MS method allows only to measure water-soluble compounds like levoglucosan. Nevertheless, analytical performances are better for the LCMS method (lower LOD, better recovery) than for the GCMS method. Moreover one of the main advantages of the LC-MS method is its rapidity, allowing the processing of large sets of samples in order to obtain data for this biomass burning marker in large field campaigns. In fact, LC-MS allows the analysis of monosaccharide anhydrides in less than five min with a shorter time of sample preparation using a cheaper and very simple extraction technique with less impact on the environment. This extraction method can also be applied to many environmental types, as for example soil whose moisture does not allow organic solvent extraction. Finally this work has shown that anion-exchange chromatography coupled with an ESI-MS/MS dectector allow the quantification of neutral species like anhydrous sugars. And in the future this method could be used to quickly characterize and quantify other organics tracers in aerosol sampling.

Acknowledgements. The authors would like to thank staffs from ASCOPARG and EDYTEM for their support during the field campaigns and Bastien Mettra for his contribution to this work. C. Piot thanks the Region Rhône-Alpes for her PhD grant.

Edited by: M. Weber

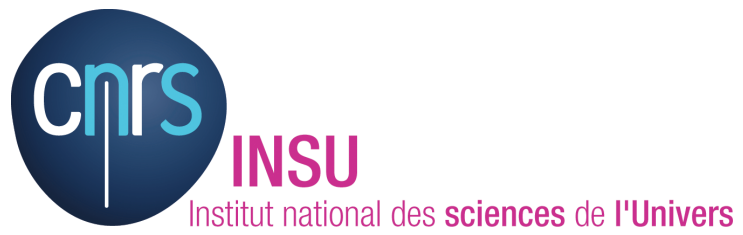

The publication of this article is financed by CNRS-INSU.

\section{References}

Bergauff, M., Ward, T., Noonan, C., and Palmer, C. P.: Determination and evaluation of selected organic chemical tracers for wood smoke in airborne particulate matter, Int. J. Environ. An. Ch., 88, 473-486, 2008.

Caseiro, A., Marr, I. L., Claeys, M., Kasper-Giebl, A., Puxbaum, H., and Pio, C. A.: Determination of saccharides in atmospheric aerosol using anion-exchange high-performance liquid chromatography and pulsed-amperometric detection, J. Chromatogr. A, 1171, 37-45, 2007.

Caseiro, A., Bauer, H., Schmidl, C., Pio, C. A., and Puxbaum, H.: Wood burning impact on $\mathrm{PM}_{10}$ in three Austrian regions, Atmos. Environ., 43, 2186-2195, 2009.

Dixon, R. W. and Baltzell, G.: Determination of levoglucosan in atmospheric aerosols using high performance liquid chromatography with aerosol charge detection, J. Chromatogr. A, 1109, 214 221, 2006.

Dye, C. and Yttri, K. E.: Determination of Monosaccharide Anhydrides in Atmospheric Aerosols by Use of HighPerformance Liquid Chromatography Combined with HighResolution Mass Spectrometry, Anal. Chem., 77, 1853-1858, doi:10.1021/ac049461j, 2005.

El Haddad, I., Marchand, N., Dron, J., Temime-Roussel, B., Quivet, E., Wortham, H., Jaffrezo, J. L., Baduel, C., Voisin, D., Besombes, J. L., and Gille, G.: Comprehensive primary particulate organic characterization of vehicular exhaust emissions in France, Atmos. Environ., 43, 6190-6198, 2009.

El Haddad, I., Marchand, N., Temime-Roussel, B., Wortham, H., Piot, C., Besombes, J.-L., Baduel, C., Voisin, D., Armengaud, A., and Jaffrezo, J.-L.: Insights into the secondary fraction of the organic aerosol in a Mediterranean urban area: Marseille, Atmos. Chem. Phys., 11, 2059-2079, doi:10.5194/acp-11-20592011, 2011a.

El Haddad, I., Marchand, N., Wortham, H., Piot, C., Besombes, J.-L., Cozic, J., Chauvel, C., Armengaud, A., Robin, D., and Jaffrezo, J.-L.: Primary sources of $\mathrm{PM}_{2.5}$ organic aerosol in an industrial Mediterranean city, Marseille, Atmos. Chem. Phys., 11, 2039-2058, doi:10.5194/acp-11-2039-2011, 2011 b.

Engling, G., Carrico, C. M., Kreidenweis, S. M., Collett Jr, J. L., Day, D. E., Malm, W. C., Lincoln, E., Min Hao, W., Iinuma, Y., and Herrmann, H.: Determination of levoglucosan in biomass combustion aerosol by high-performance anion-exchange chromatography with pulsed amperometric detection, Atmos. Environ., 40, 299-311, 2006.

Fabbri, D., Marynowski, L., Fabianìska, M. J., Zatonì, M., and Simoneit, B. R. T.: Levoglucosan and Other Cellulose Markers in Pyrolysates of Miocene Lignites: Geochemical and Environmental Implications, Environ. Sci. Technol., 42, 2957-2963, doi:10.1021/es7021472, 2008.

Favez, O., Cachier, H., Sciare, J., Sarda-Estève, R., and Martinon, L.: Evidence for a significant contribution of wood burning aerosols to $\mathrm{PM}_{2.5}$ during the winter season in Paris, France, Atmos. Environ., 43, 3640-3644, 2009.

Favez, O., El Haddad, I., Piot, C., Boréave, A., Abidi, E., Marchand, N., Jaffrezo, J.-L., Besombes, J.-L., Personnaz, M.-B., Sciare, J., Wortham, H., George, C., and D'Anna, B.: Inter-comparison of source apportionment models for the estimation of wood burning aerosols during wintertime in an Alpine city (Grenoble, France), Atmos. Chem. Phys., 10, 5295-5314, doi:10.5194/acp-10-52952010, 2010.

Fine, P. M., Cass, G. R., and Simoneit, B. R. T.: Chemical Characterization of Fine Particle Emissions from the Fire- 
place Combustion of Wood Types Grown in the Midwestern and Western United States, Environ. Eng. Sci., 21, 387-409, doi:10.1089/109287504323067021, 2004.

Fraser, M. P. and Lakshmanan, K.: Using Levoglucosan as a Molecular Marker for the Long-Range Transport of Biomass Combustion Aerosols, Environ. Sci. Technol., 34, 4560-4564, doi:10.1021/es9912291, 2000.

Gaeggeler, K., Prevot, A. S. H., Dommen, J., Legreid, G., Reimann, S., and Baltensperger, U.: Residential wood burning in an Alpine valley as a source for oxygenated volatile organic compounds, hydrocarbons and organic acids, Atmos. Environ., 42, 82788287, 2008.

Gambaro, A., Zangrando, R., Gabrielli, P., Barbante, C., and Cescon, P.: Direct Determination of Levoglucosan at the Picogram per Milliliter Level in Antarctic Ice by HighPerformance Liquid Chromatography/Electrospray Ionization Triple Quadrupole Mass Spectrometry, Anal. Chem., 80, 16491655, doi:10.1021/ac701655x, 2008.

Hennigan, C. J., Sullivan, A. P., Collett Jr., J. K., and Robinson, A. L.: Levoglucosan stability in biomass burning particles exposed to hydroxyl radicals, Geophys. Res. Lett., 37, L09806, doi:10.1029/2010GL043088, 2010.

Hoffman, D., Tilgner, A., Iinuma, Y., and Herrmann, H.: Atmospheric stability of levoglucosan: A detailed laboratory and modeling study, Environ. Sci. Technol., 44, 694-699, 2010.

Hornig, J. F., Soderberg, R. H., Barefoot, A. C., and Galasyn, J. F.: Wood smoke analysis: vaporization losses of PAH from filters and levoglucosan as a distinctive marker for wood smoke, Polynuclear Aromatic Hydrocarbons: Mechanisms, Methods, and Metabolism, edited by: Cooke, M. and Dennis, A. J., Battelle Press, Columbus, 561-568, 1985.

Iinuma, Y., Engling, G., Puxbaum, H., and Herrmann, H.: A highly resolved anion-exchange chromatographic method for determination of saccharidic tracers for biomass combustion and primary bio-particles in atmospheric aerosol, Atmos. Environ., 44, 13671371, 2009.

Locker, H. B.: The use of levoglucosan to assess the environmental impact of residential wood-burning on air quality, Dartmouth College, Hanover, 137 pp., 1988.

Otto, A., Gondokusumo, R., and Simpson, M. J.: Characterization and quantification of biomarkers from biomass burning at a recent wildfire site in Northern Alberta, Canada, Appl. Geochem., 21, 166-183, 2006.

Palma, P., Cappiello, A., De Simoni, E., Mangani, F., Trufelli, H., Decesari, S., Facchini, M. C., and Fuzzi, S.: Identification of Levoglucosan and Related Steroisomers in Fog Water as a Biomass Combustion Tracer by ESI-MS/MS, Ann. Chim., 94, 911-919, 2004.

Piot, C.: Polluants atmosphériques particulaires en Rhône-Alpes : caractérisation chimique et sources d'émissions, Universités de Grenoble, France, PhD thesis, 2011.

Piot, C., Jaffrezo, J.-L., and Besombes, J.-L.: Comparison between LC-MS and GC-MS measurements for the determination of levoglucosan and its application to rural and urban atmospheric samples, European Aerosol Conference, Karlsruhe, Germany, 2009,

Piot, C., Jaffrezo, J.-L., Cozic, J., El Haddad, I., Marchand, N., Personnaz, M.-B., and Besombes, J.-L.: Caractérisation chimique des aérosols en région Rhône-Alpes: étude de l'influence des différentes sources d'émissions par une approche multi-traceurs, Pollution Atmosphérique, 211, 313-318, 2011.

Puxbaum, H., Caseiro, A., Sánchez-Ochoa, A., Kasper-Giebl, A., Claeys, M., Gelencsér, A., Legrand, M., Preunkert, S., and Pio, C.: Levoglucosan levels at background sites in Europe for assessing the impact of biomass combustion on the European aerosol background, J. Geophys. Res., 112, D23S05, doi:10.1029/2006jd008114, 2007.

Saarnio, S., Teinilä, K., Aurela, M., Timonen, H., and Hillamo, R.: High-Performance anion-exchange chromatography - mass spectrometry method for determination of levoglucosan, mannosan, and galactosan in atmospheric fine particulate matter, Anal. Bioanal. Chem., 398, 2253-2264, 2010.

Schkolnik, G., Falkovich, A. H., Rudich, Y., Maenhaut, W., and Artaxo, P.: New Analytical Method for the Determination of Levoglucosan, Polyhydroxy Compounds, and 2-Methylerythritol and Its Application to Smoke and Rainwater Samples, Environ. Sci. Technol., 39, 2744-2752, doi:10.1021/es048363c, 2005.

Schmidl, C., Marr, I. L., Caseiro, A., Kotianová, P., Berner, A., Bauer, H., Kasper-Giebl, A., and Puxbaum, H.: Chemical characterisation of fine particle emissions from wood stove combustion of common woods growing in mid-European Alpine regions, Atmos. Environ., 42, 126-141, 2008.

Simoneit, B. R. T.: Biomass burning - a review of organic tracers for smoke from incomplete combustion, Appl. Geochem., 17, 129-162, 2002.

Simoneit, B. R. T., Schauer, J. J., Nolte, C. G., Oros, D. R., Elias, V. O., Fraser, M. P., Rogge, W. F., and Cass, G. R.: Levoglucosan, a tracer for cellulose in biomass burning and atmospheric particles, Atmos. Environ., 33, 173-182, 1999.

Simoneit, B. R. T., Elias, V. O., Kobayashi, M., Kawamura, K., Rushdi, A. I., Medeiros, P. M., Rogge, W. F., and Didyk, B. M.: Sugars Dominant Water-Soluble Organic Compounds in Soils and Characterization as Tracers in Atmospheric Particulate Matter, Environ. Sci. Technol., 38, 59395949, doi:10.1021/es0403099, 2004.

Szidat, S., Jenk, T. M., Synal, H.-A., Kalberer, M., Wacker, L., Hajdas, I., Kasper-Giebl, A., and Baltensperger, U.: Contributions of fossil fuel, biomass-burning, and biogenic emissions to carbonaceous aerosols in Zurich as traced by 14C, J. Geophys. Res., 111, D07206, doi:10.1029/2005jd006590, 2006.

Wan, E. C. H. and Yu, J. Z.: Determination of sugar compounds in atmospheric aerosols by liquid chromatography combined with positive electrospray ionization mass spectrometry, J. Chromatogr. A, 1107, 175-181, 2006.

Yttri, K. E., Dye, C., Braathen, O.-A., Simpson, D., and Steinnes, E.: Carbonaceous aerosols in Norwegian urban areas, Atmos. Chem. Phys., 9, 2007-2020, doi:10.5194/acp-9-2007-2009, 2009.

Zdráhal, Z., Oliveira, J., Vermeylen, R., Claeys, M., and Maenhaut, W.: Improved Method for Quantifying Levoglucosan and Related Monosaccharide Anhydrides in Atmospheric Aerosols and Application to Samples from Urban and Tropical Locations, Environ. Sci. Technol., 36, 747-753, doi:10.1021/es015619v, 2002.

Zheng, M., Cass, G. R., Schauer, J. J., and Edgerton, E. S.: Source Apportionment of PM2.5 in the Southeastern United States Using Solvent-Extractable Organic Compounds as Tracers, Environ. Sci. Technol., 36, 2361-2371, doi:10.1021/es011275x, 2002. 